\title{
APLIKASI PENENTUAN NOMOR URUT ANTRIAN RUMAH SAKIT MELALUI SMS GATEWAY
}

\author{
Sofi Nur Rochmawati ${ }^{1}$, Firman Nurdiyansyah ${ }^{2}$ \\ sofinur_rochmawati@yahoo.co.id, firmannurdiyansyah7@gmail.com \\ Universitas Widyagama Malang
}

\begin{abstract}
The research aims to develop software Information System Web-Based in hospital. As a system that can provide the necessary information easily and then implemented in the form of programs. This reserach was conducted by the method of analysis, design and making program. Application developed by the Web, uses a MySQL database and SMS Gateway. It can useful for patients who want treatment in hospital.
\end{abstract}

Intisari- Penelitian ini bertujuan untuk mengembangkan perangkat lunak Sistem Informasi Berbasis Web di rumah sakit. Sebagai sebuah sistem yang dapat memberikan informasi yang diperlukan dengan mudah dan kemudian diimplementasikan dalam bentuk program. penelitian ini dilakukan dengan metode analisis, desain dan pembuatan program. Aplikasi yang dikembangkan oleh Web, menggunakan database MySQL dan SMS Gateway. Hal ini dapat berguna untuk pasien yang ingin berobat di rumah sakit.

\section{Kata Kunci-Information System, Web, SMS Gateway}

\section{PENDAHULUAN}

Di era teknologi yang berkembang pesat saat ini, masih banyak instansi atau perusahaan yang belum memanfaatkan teknologi untuk memberikan kemudahan bagi para pemakainya. Kesadaran masyarakat tentang keteraturan dan ketertiban juga masih jauh dari sempurna. Hidup antri yang diterapkan di lingkungan instansi atau perusahaan seperti rumah sakit yang memiliki banyak pasien. Banyak pasien yang merasa tidak mendapatkan pelayanan yang baik sebab sistem antrian yang masih konvensional.

Masalah yang sering dihadapi adalah ke-tidak efisien dalam hal waktu dan penggunaan kertas untuk nomor antrian pasien.Tidak efisien dalam hal waktu di karenakan pasien harus datang lebih awal dan menunggu antrian yang panjang sehingga banyak pasien yang memutuskan untuk pulang terlebih dahulu sehingga memerlukan biaya transportasi $2 \mathrm{x}$ lipat. Dan rumah sakit banyak membuang kertas hanya untuk nomor antrian yang membuat limbah kertas semakin banyak. Semakin banyak limbah, maka lambat laun akan terjadi global warming karena limbah yang tak terpakai.

Penyelesaian dalam masalah ini yaitu dibuatnya "Aplikasi Penentuan Nomor Urut Antrian Rumah Sakit Melalui SMS Gateway" sehingga pasien tidak perlu datang ke rumah sakit untuk mengambil nomor antrian dan pasien dapat menghemat biaya transportasi. Dan rumah sakit dapat menghemat pengeluaran kertas. Sehingga dapat memperkecil limbah kertas yang masih banyak saat ini. Maka rumah sakit tersebut dapat memperkecil penebangan pohon untuk dijadikan kertas.

\section{A. Teori Antrian}

\section{LANDASAN TEORI}

Teori antrian adalah teori yang menyangkut studi matematis dari antrian -antrian atau baris-baris penungguan (Labolo). Menurut Pangestu Subagyo (Subagyo, Handoko, \& Asri, 2005)antrian adalah kumpulan dari masukan atau obyek yang menunggu pelayanan Kerangka Pemikiran. Dalam pangestu (Subagyo, Handoko, \& Asri, 2005)dijelaskan bahwa teori tentang antrian diketemukan dan dikembangkan oleh A. K. Erlang, seorang insinyur dari Denmark yang bekerja pada perusahaan telepon di Kopenhagen pada tahun 1910. Erlang melakukan eksperimen tentang fluktuasi permintaan fasilitas telepon yang berhubungan dengan automatic dialing equipment, yaitu peralatan penyambungan telepon secara otomatis.

\section{B. Struktur Antrian}

Ada 4 Model antrian dasar yang umum terjadi dalam sebuah sistem antrian

(Gross \& Harris, The Queueing Systems, 1984).

1. Single Chanel-Single Phase

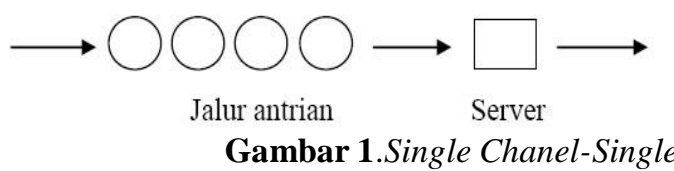

Phase

Sumber : (Gross \& Harris, The Queueing Systems, 1984)

Single Channel berarti hanya ada satu jalur yang memasuki sistem pelayanan atau ada satu fasilitas pelayanan. Single Phase berarti hanya ada satu fasilitas pelayanan.

2. Single Chanel-Multi Phase

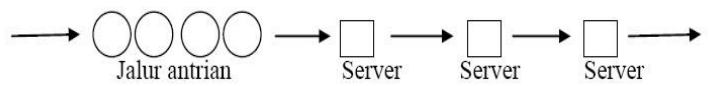

Gambar 2.Single Chanel-Multi Phase

Sumber : (Gross \& Harris, The Queueing Systems, 1984)

Sistem antrian jalur tunggal dengan tahapan berganda ini atau menunjukkan ada dua atau lebih pelayanan yang dilaksanakan secara berurutan.

3. Multi Chanel-Single Phase 


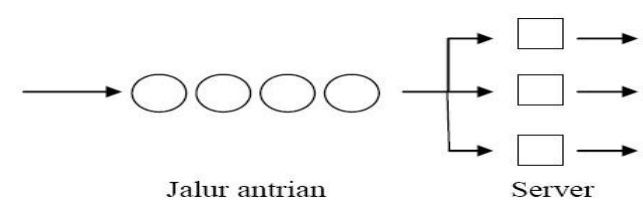

Gambar 3.Multi Chanel-Single Phase

Sumber : (Gross \& Harris, The Queueing Systems, 1984)

Sistem Multi Channel - Single Phase terjadi di mana ada dua atau lebih fasilitas pelayanan dialiri oleh antrian tunggal.

4. Multi Chanel-Multi Phase

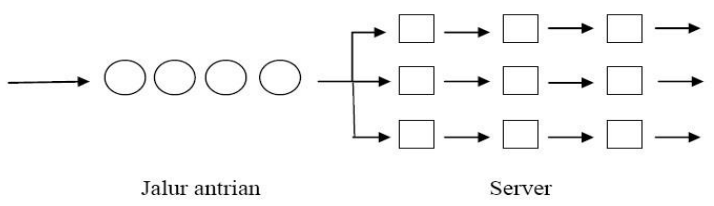

Gambar 4.Multi Chanel-Multi Phase

Sumber : (Gross \& Harris, The Queueing Systems, 1984)

Sistem Multi Channel - Multi Phase ini menunjukkan bahwa setiap sistem mempunyai beberapa fasilitas pelayanan pada setiap tahap sehingga terdapat lebih dari satu pelanggan yang dapat dilayani pada waktu bersamaan.

\section{Short Message Service}

SMS merupakan fitur ponsel yang dapat digunakan untuk mengirimkan dan menerima pesan berupa teks.Tiga kategori umum SMS, yaitu point-to-point, point-to-multipoint, dan broadcast (Harte, Levine, \& Livingston, 1999).

\section{SMS Gateway}

Merupakan jenis aplikasi SMS dua arah, dengan keunikan semua tarif yang diberlakukan adalah tarif SMS normal sesuai dengan apa yang diberlakukan oleh operator. Karena sifatnya yang dua arah, maka jenis SMS ini sangat cocok dijadikan sebagai SMS center organisasi atau institusi tertentu (Sadeli, 2012).

Ataupun sebuah aplikasi SMS Gateway dapat menggunakan jalur SMSC untuk pengoperasiannya. Keuntungannya adalah penggunaan nomor pendek yang mungkin terdiri dari 3 atau 4 digit saja, misalnya 222, 6060 dan seterusnya. (Sasongko \& Santoso, 2008).

\section{E. Web}

Web adalah suatu bagian yang tidak dapat dipisahkan dari dunia internet. Web dapat terdiri atas berbagai kumpulan halaman untuk menampilkan informasi berupa teks, gambar diam atau gerak, animasi, suara atau gabungan dari semuanya. Berdasarkan pada fungsinya, website terbagi atas : (Hidayat \& Rahmat, 2010)

1. Personal Website, yang berisi informasi pribadi seseorang

2. Commercial Website, merupakan website milik instansi pemerintah ataupun pendidikan umum dan bertujuan memberikan pelayanan kepada penggunanya.
3. Government Website, merupakan website milik instansi pemerintah ataupun pendidikan umum dan bertujuan memberikan pelayanan kepada penggunanya.

4. Non-Profit Organization Website, merupakan website milik suatu organisasi atau instansi, namun tidak digunakan untuk kegiatan bisnis (bersifat non-profit).

\section{F. HTML}

Aplikasi web yang paling dasar ditulis menggunakan HTML. Sebagaimana diketahui, HTML (hypertext markup language) adalah bahasa standar untuk membuat halamanhalaman web, sebagai contoh, berikut adalah kode HTML (disimpan dengan ekstensi .htm atau .html). (Aziz, Riza, \& Tulloh, 2015).

\section{G. PHP}

PHP merupakan bahasa pemrograman yang paling populer dan banyak digunakan untuk pemrograman web, PHP disebut juga pemrograman server side, artinya program dijalankan pada server.Skema yang memungkinkan suatu aplikasi berinteraksi dengan database menggunakan PHP. (Aziz, Riza, \& Tulloh, 2015)

\section{H. Database MySQL}

MySQL merupakan database multiuser yang menggunakan bahasa Structure Query Language (SQL). MySQL dalam operasi client-server, melibatkan serverdaemon MySQL di sisi server dan berbagai macam program, serta library yang berjalan di sisi client. MySQL mampu menangani data yang cukup besar. (Aziz, Riza, \& Tulloh, 2015).

\section{Gammu SMS Gateway}

Gammu adalah aplikasi yang dapat digunakan untuk mengelola berbagai fungsi pada handphone, modem dan perangkat sejenis lainnya. Fungsi-fungsi yang dapat dikelola oleh Gammu antara lain adalah fungsi nomor kontak (phonebook) dan fungsi SMS. Namun, untuk aplikasi yang akan kita kembangkan ini, kita akan lebih banyak menggunakan fungsi SMS dari Gammu. (Aziz, Riza, \& Tulloh, 2015).

\section{ANALISA DAN PERANCANGAN SISTEM}

\section{A. Analisis Sistem Yang Berjalan}

Dalam membuat suatu program diperlukan tahapan analisis sistem yang sedang berjalan. Analisis sistem yang berjalan bertujuan untuk mengetahui bagaimana jalannya sistem yang telah diterapkan serta untuk mengetahui masalahmasalah yang timbul dari sistem yang diterapkan tersebut sebagai landasan dalam merancang sistem yang diusulkan.

Sistem informasi pelayanan antrian pasien yang sedang berjalan pada rumah sakit masih dilakukan secara konvensional dimana pada proses antrian pasien masih menggunakan kertas untuk menentukan nomor antrian pasien. Hal ini menyulitkan pasien rumah sakit karena akan menyita waktu pasien, khususnya bagi pasien yang bertempat tinggal jauh dari rumah sakit. Selanjutnya pada proses pemberian 
kartu antrian bisa jadi terdapat kecurangan dari pihak petugas. Seperti memperjual-belikan kertas antrian kepada pasien yang baru datang sehingga pasien tersebut mendapatkan nomor antrian terlebih dahulu.

\section{B. Gambaran Umum (Flowchart)}

Gambaran umum sistem aplikasi dari sisi pasien yang menggunakan website maupun sms gateway yang dikirm oleh sisi petugas dapat terlihat dari flowchart berikut.

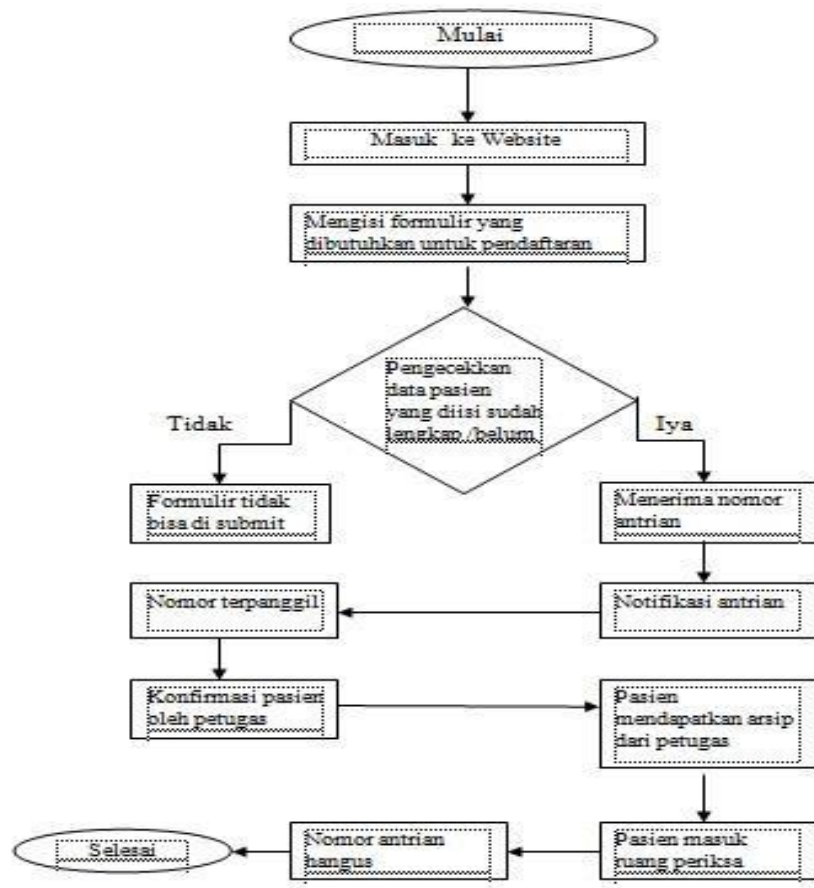

Gambar 6 . Flow chart dari sisi parien

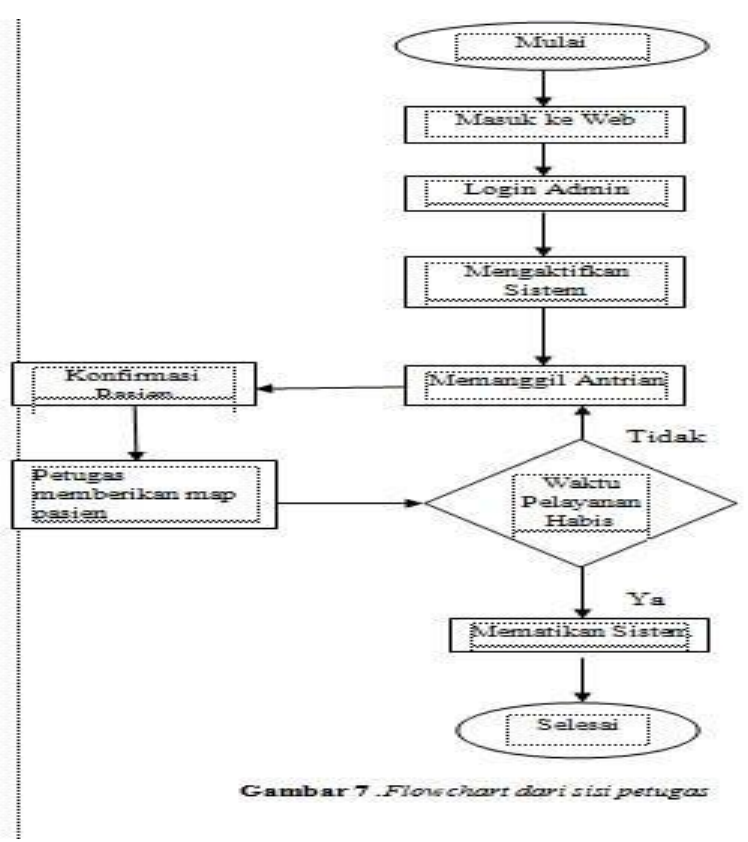

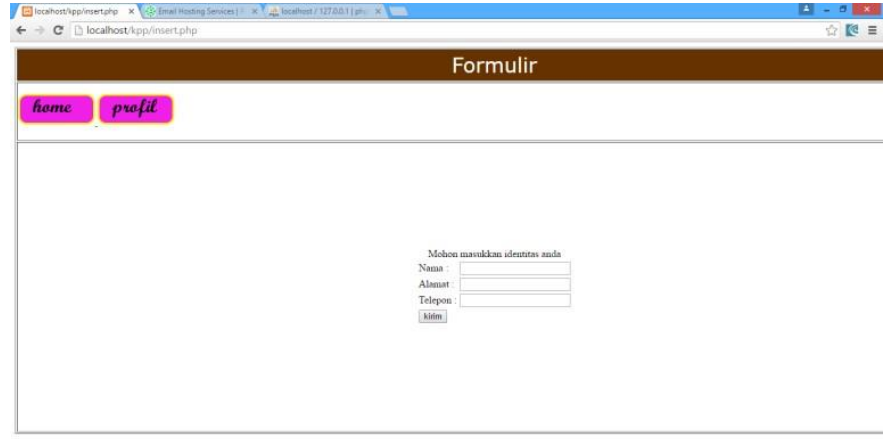

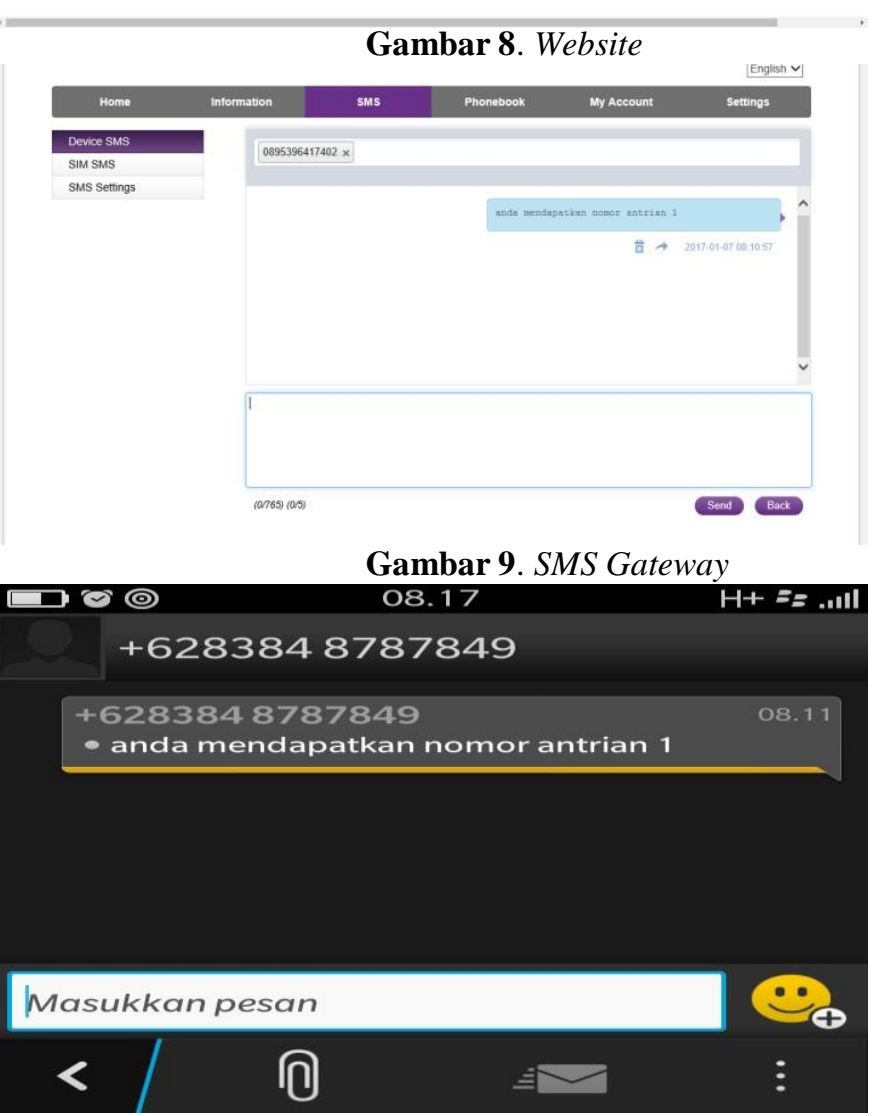

Gambar 10. Contoh SMS

\section{KESIMPULAN}

Kesimpulan yang dapat diambil dengan adanya "Penentuan Nomor Urut Antrian Rumah Sakit Melalui SMS Gateway” yaitu:

1. Dengan penentuan nomor urut antrian pasien tidak terlalu repot datang ke rumah sakit dan dari pihak rumah sakit.

2. Tahap perancangan dari sistem yang dikembangkan adalah membuat gambaran umum flowchart dari sisi pasien dan petugas.

3. Aplikasi penentuan nomor urut yang telah dibuat berbasis $w e b$, penyajian nomor antrian secara online dan dapat langung diakses oleh pasien dimanapun berada. 


\section{DAFTAR PUSTAKA}

[1]Aziz, S. B., Riza, T. A., \& Tulloh, R. (2015, Juli). Perancangan Dan Implementasi Aplikasi Sistem Antrian Untuk Pasien Pada Dokter Umum Berbasis Android Dan SMS Gateway. Elektro Telekomunikasi Terapan . [2]Chrisdianto, P. R., \& Sevani, N. (2014). Pencetakan Dokumen Melalui Web Dan SMS. Teknik dan Ilmu Komputer, 03.

[3]Dharwiyanti, S. (2003). Pengantar Unified Modelling Language(UML). [4]Gross, \& Harris. (1984). The Queueing Systems. Inc , 4.

[5]Harte, L., Levine, R., \& Livingston, G. (1999). GSM Superphone.

McGraw-Hill

[6]Hidayat, \& Rahmat. (2010). Cara Praktis Membangun Website Gratis. Jakarta: PT.Elex Media Komputindo.

[7]Labolo, I. (n.d.). Penerapan SMS Gateway Untuk Sistem Antrian Pasien Pada Praktek Dokter Umum dan Spesialis. STMIK Ichsan Gorontalo .

[8]Pangestu, Handoko, \& Asri. (2005). Dasar-Dasar Operation Research. $B P F E$.

[9]Sadeli, M. (2012). Aplikasi SMS dengan Visual Basic 6.0 dan Visual Basic 2010. Maxikom .

[10]Sasongko, J., \& Santoso, D. B. (2008). Konsep Dasar SMS Gateway dan Aplikasi SMS menggunakan Visual Basic 6 dan FBUS Lite. Teknologi Informasi DINAMIK, XIII.

[11]Subagyo, P., Handoko, T. H., \& Asri, M. (2005). Dasar-dasar Operation Research. BPFE. 